\title{
An investigation into the effects of British Summer Time on road traffic accident casualties in Cheshire
}

\author{
J D Whittaker
}

\begin{abstract}
Objective-To assess the effect of British Summer Time (BST) on road traffic accident casualties and to analyse whether the introduction of year round BST would result in reductions in casualty numbers. Design-A comparative study of road traffic accident data from before and after the onset of BST.

Setting-The county of Cheshire.

Subjects-Data from a total of 4185 casualties from the period 1983 to 1993 .

Main outcome measures-The effect of BST on both vehicle, cycle, and pedestrian casualties and casualties among schoolchildren.
\end{abstract}

Results-The onset of BST in spring was associated with reductions in casualty numbers of $6 \%$ in the morning and $11 \%$ in the evening. The anticipated rise in casualties with the darker mornings was not seen and as reductions were maximal in the pedestrian $(36 \%)$, cyclist $(11 \%)$, and schoolchild $(24 \%)$ subgroups they were presumed to be due to an altered reliance on vehicular transport. The change back to Greenwich Mean Time (GMT) in autumn produced an anticipated reduction $(6 \%)$ in casualties in the lighter mornings. The darker evenings, as predicted, were associated with significant increases in casualties $(4 \%)$, mainly vehicle $(5 \%)$ and pedestrian $(8 \%)$ casualties. There was an overall net reduction in casualty numbers when the analysed periods of BST were compared to those during GMT.

Conclusions-The use of BST in Cheshire over the period studied was associated with reductions in casualty figures. The application of these results nationally may be expected to produce more and less pronounced changes the further north or south, respectively, the area studied. The introduction of year-long BST would result in beneficial effects on road traffic accident casualties.

( 7 Accid Emerg Med 1996;13:189-192)

Accident and Emergency

Department, Countess

of Chester Hospital, Liverpool Road, Chester CH2 1BQ

J D Whittaker

Correspondence to: Mr Jon Whittaker
Summer Time (BST) is introduced by moving the clock forwards to one hour ahead of Greenwich Mean Time (GMT). In the autumn the clock is moved backwards by one hour to revert to GMT. This produces a shift in daylight hours, resulting in a later dawn and dusk.

The introduction of BST in 1916 was an attempt to make the most of daylight hours to reduce fuel consumption during wartime. Since its introduction, the use of BST has been a highly contentious subject and thus there have been several experimental changes to the normal protocol. In the years 1941 to 1945 and again in 1947 there was an experimental doubling of BST, and between 1968 and 1971 BST was maintained over the winter months (British Standard Time). In the last decade there have been calls from various parties for the abandonment of BST, the return of British Standard Time, ${ }^{12}$ and the introduction of Double British Summer Time. ${ }^{3}$

The alteration in daylight hours with respect to the fixed periods of the rush hours of commuter traffic may be expected to produce alterations in the patterns of road traffic accident statistics. The objective of this study was therefore to analyse the effects of BST on the frequencies and types of road traffic accident casualties in Cheshire.

\section{Methods}

An 11 year period from 1983 to 1993 was chosen and data were acquired from a database held at the Cheshire Road Safety Unit. The database has been compiled from road accident report forms (STATS 19) completed for every road traffic accident reported to the police.

The area of study comprised the county of Cheshire, which covers a total land area of 900 square miles, extending from Warrington in the north to Nantwich in the south. The geography of the area includes the city of Chester at its centre, a large rural population, and an extensive industrial base at Ellesmere Port. The road network in Cheshire encompasses an extensive motorway system (M6, M56, M53) and class $A$ and $B$ roads with a total road distance of $5815 \mathrm{~km}$.

Standard records were consulted for the dates of BST in the years 1983 to 1993 . From this information, one week periods either side of the change to and from BST were selected for each year. Daily time intervals were chosen from 05.00 to 09.00 and 15.00 to 19.00 over each two week period. These intervals corresponded with the hours around sunrise and sunset for the time of year and also with the 


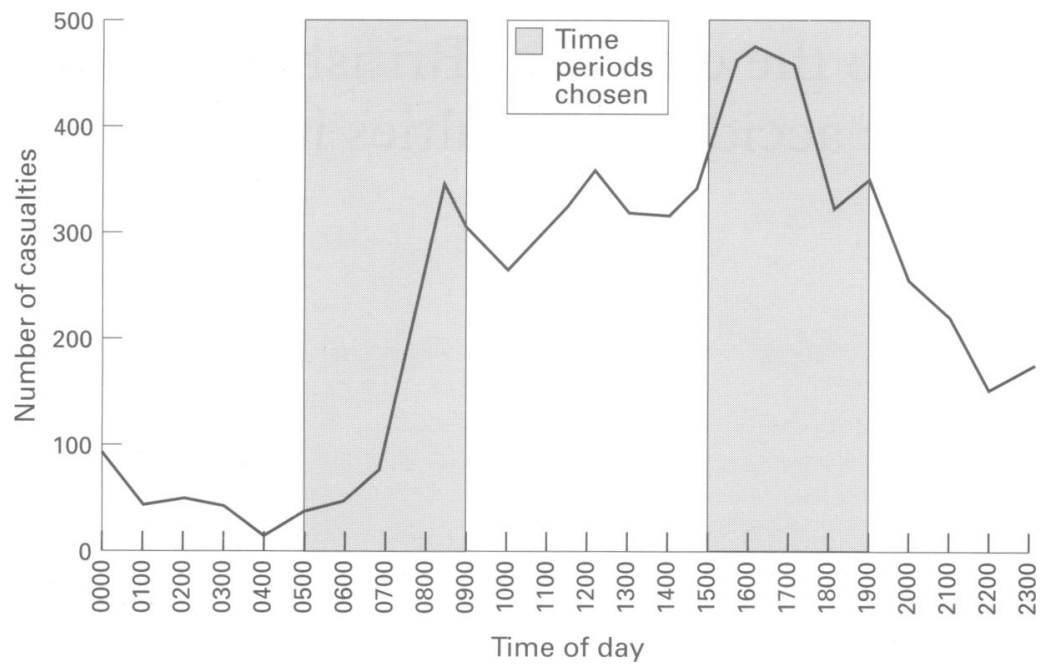

Figure 1 Frequency of road traffic accident casualties per hour, Cheshire 1983-1993.

daily peaks in road traffic accidents in Cheshire over the years 1983 to 1993 (fig 1). Similar patterns in road traffic accidents have been described nationally and locally in the north and south of England. ${ }^{4-6}$

Data were subdivided into category of road user (vehicle, cycle, pedestrian) and age of the casualty, concentrating on children of school age (age groups 5-11 and 12-16 years). The category of "vehicles" includes cars, motorcycles, and heavy goods vehicles. Comparison of casualty numbers with cumulative data from other months of the year over the 11 year period showed no significant differences (fig 2). The severity of injury of the casualty was not assessed, as this judgement is made by the police officer at the scene of an accident and has been shown to result in an inaccurate evaluation. ${ }^{7}$

The significance of differences was estimated by $\chi^{2}$ analysis with Yates correction if appropriate.

\section{Results}

During the period of the study, data from 4185 casualties were analysed. The data were divided into two groups, the first for the onset of BST in spring (1904 casualties, 45.5\%) and the second for the reversion back to GMT in autumn (2281 casualties, 54.5\%). The total

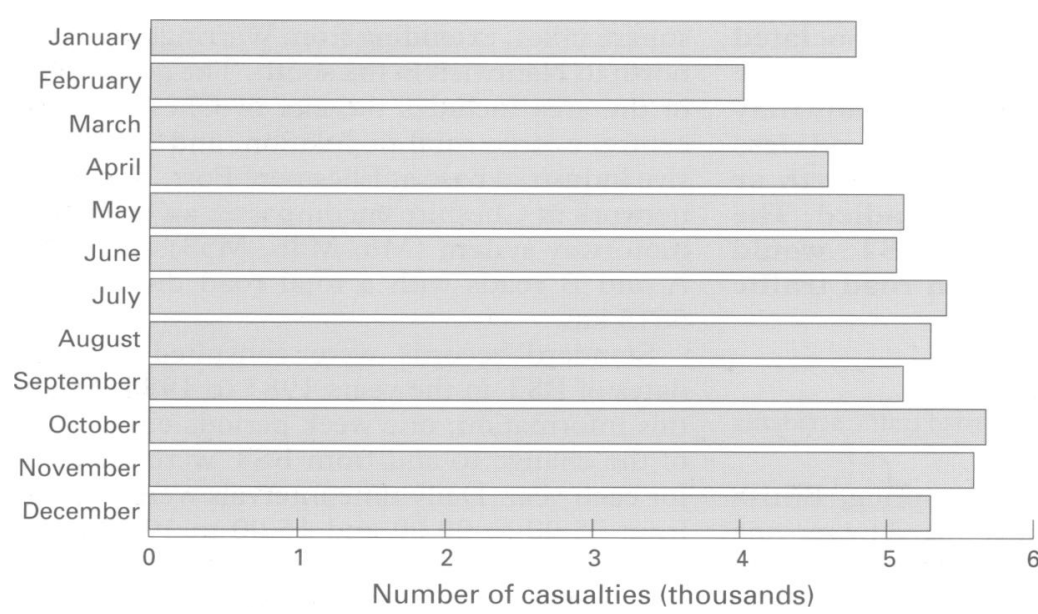

Figure 2 Road traffic accidents in Cheshire per month, 1983-1993. numbers of casualties over the 11 year period in each subdivision are shown in table 1 .

In the spring there were reductions in the total numbers of casualties in both morning and evening periods, with 96 fewer casualties $(P<0.05)$ reported in the week following the onset of BST.In the autumn the picture was not as clear. In the week following the reversion back to GMT there was a $6.3 \%$ reduction in casualty numbers in the morning period but with a $3.9 \%$ increase in numbers in the corresponding evening period. The overall effect was a non-significant increase of seven casualties.

Comparison of the respective morning and evening periods of the spring and autumn shows concordance between the reductions in casualty numbers in the morning periods but an increase $(P<0.05$, odds ratio $1 \cdot 17,95 \%$ confidence interval 1.01 to 1.35 ) in total casualties in the autumn evening period as compared with the spring evening period.

On analysis of the category of road user there were 613 pedestrian casualties $(14.6 \%), 517$ cycle casualties $(12 \cdot 3 \%)$, and 3055 vehicle casualties $(73 \%)$. There were no statistically significant changes, but obvious trends can be identified. With the onset of BST in the spring morning and evening periods there were reductions in all groups (mean reduction $15.5 \%$, range $8.0 \%$ to $36 \cdot 1 \%$ ) with the exception of the vehicle users in the spring morning period, where no difference was shown.

In the autumn morning period numbers were reduced in all groups (mean reduction $15.4 \%$, range $1 \cdot 1 \%$ to $25.7 \%$ ) following the reversion to GMT. In the evening period there were increased casualty numbers in the pedestrian group $(7 \cdot 6 \%)$ and the vehicle group $(4 \cdot 6 \%)$, with a small reduction in cyclists (3.9\%) (table 2).

On analysis of the age groups 5 to 11 and 12 to 16 years, there were 350 casualties aged 5 to 11 years $(8 \cdot 4 \%)$ and 428 casualties aged 12 to 16 years $(10 \cdot 2 \%)$. There were non-significant reductions in the numbers of casualties in all age groups in the spring morning and evening periods in the week after the change to BST (mean reduction $24 \cdot 2 \%$, range $20 \%$ to $30 \%$ ), with the exception of the age 12 to 16 age group in the evening period (no change).

In the autumn period there was a $12.5 \%$ reduction in casualty numbers in the morning period in the younger age group, with no change in the age 5 to 11 year group. The autumn evening period showed a $10.5 \%$ increase in casualty numbers in the 5 to 11 year group, with a $20.9 \%$ reduction in the 12 to 16 year age group (table 2 ).

The onset of BST in spring was associated with reductions or no change in casualty numbers in all the subgroups studied and increases in casualty numbers were seen only in the autumn evening period with the shift back to GMT.

\section{Discussion}

Following the experimental use of British Standard Time from 1968 to 1971 it was reported that this had resulted in a reduction in the number of people killed or seriously injured 
Table 1 Total road traffic accident casualty numbers for each specified time period

\begin{tabular}{llccll}
\hline & $\begin{array}{l}\text { 1 week before } \\
\text { change }\end{array}$ & $\begin{array}{l}\text { 1 week after } \\
\text { change }\end{array}$ & $\begin{array}{l}\text { Percentage } \\
\text { change }\end{array}$ & Significance \\
\hline Spring & Morning period & 277 & 260 & $-6 \cdot 14 \%$ & $\mathrm{NS}$ \\
& Evening period & 723 & 644 & $-10.93 \%$ & $\mathrm{P}<0.05$ \\
& Total & 1000 & 904 & $-9.6 \%$ & $\mathrm{P}<0.05$ \\
\multirow{4}{*}{ Autumn } & Morning period & 368 & 345 & $-6.25 \%$ & $\mathrm{NS}$ \\
& Evening period & 769 & 799 & $+3.9 \%$ & $\mathrm{NS}$ \\
& Total & 1137 & 1144 & $+0.62 \%$ & $\mathrm{NS}$ \\
\hline
\end{tabular}

in road traffic accidents of approximately 1350 per annum. ${ }^{8}$ Further analysis suggested that should British Standard Time be introduced it would result in a reduction of 580 deaths or seriously injured casualties per annum. ${ }^{2}$ Recent work on Double British Summer Time has estimated this reduction to be 810 casualties per annum with an economic saving of $£ 90$ million at 1987 prices, based on official valuations of road accidents. ${ }^{3}$ There have been no recent attempts to quantify the effects on different categories of casualties from road traffic accidents from the present use of BST.

In the spring the clocks advance one hour, resulting in a darker morning. It may be anticipated that this change would result in an increase in the number of road traffic accidents during this period due to poorer travelling conditions. This predicted increase was not seen in any of the groups studied or as a whole, and it can be seen that there is a reduction in numbers of casualties in all but one group (vehicles - no change). In a previous study this morning period was associated with increases in casualty figures. ${ }^{8}$ This may reflect the darker morning and the modern trend of a diminishing use of cycles and walking as a means of getting to work or school, with reliance instead on vehicular transport. The resulting delaying of dusk by one hour in the spring results in improved lighting and driving conditions at peak commuter times and therefore presumed reductions in casualty numbers. It can be seen that this was confirmed by reductions, or no change (12 to 16 year group), in casualty numbers as a whole and in all subpopulations.

The restoration of GMT in the autumn results in lighter mornings and darker evenings. It may be anticipated that a lighter morning is associated with a fall in casualty numbers and this was confirmed in all the populations studied save one (age 5 to 11 - no change). This benefit of the change back to GMT must be weighed against the resultant darker evenings which, as expected, were accompanied by a significant increase in the total number of casualties. This increase in numbers was mainly due to the $7 \cdot 6 \%$ increase in pedestrian casualties and the $4.6 \%$ increase in vehicle casualties. There are apparently paradoxical reductions in casualty numbers in the cyclist and the 12 to 16 year groups. These reductions may be due to alteration in behaviour patterns, as fewer 12 to 16 year olds and cyclists are outdoors in the darker evenings. It can be seen that the overall effect of the change back to GMT was therefore a rise in casualty numbers of $0.6 \%$.

The data collected in this study are subject to a number of variables and possible inaccuracies. The use of comparative data from time periods before and after the change in hours is open to bias from weather conditions, road lighting, traffic volumes, and school holidays. Over the 11 year period it is anticipated that errors resulting from these variables will be self correcting. The start of BST coincides with the spring equinox, but it ends approximately one month after the autumn equinox. This disparity results in longer days in March than in October and thus the effect of moving the clocks is less marked. The demonstrated changes in casualty numbers may therefore be an underestimate of the reductions that would result from the introduction of British Standard Time.

Data collected are dependent on police statistics and therefore rely on accidents being reported to the police. This factor has been shown to result in underreporting of road traffic accident casualty numbers of between $25 \%$ and $43 \%$ for vehicle accidents, ${ }^{79}$ up to $97 \%$ for cycling accident, ${ }^{9}$ and $16 \%$ for pedestrian accidents. ${ }^{10}$ Consequently any proven benefits of the use of BST may be magnified by a significant percentage. At present the only reliable source of data on road traffic accident casualties is the STATS 19 forms. This will remain the case until mechanisms are in place whereby information on road traffic accident casualty numbers are recorded uniformly by accident and emergency departments and gathered centrally.

As the incidence of road traffic accidents increases over the day, peaking in the early evening in both Cheshire (fig 1) and nationally, ${ }^{4}$ a movement of one daylight hour from morning to evening will have maximum benefit on this peak, with consequent reductions in casualty numbers. This effect has already been shown to be more pronounced the further north the location. ${ }^{2}{ }^{8}$ The position of Cheshire in the British isles provides a central view of the changes that BST have on road traffic accident casualties in a specified area and it can be surmised that effects further north and south may be more and less marked, respectively. The mix of rural, urban, and industrial centres in this area implies that the

Table 2 Casualty numbers by category of road user for each specified time period

\begin{tabular}{|c|c|c|c|c|c|c|c|c|c|c|c|}
\hline \multicolumn{2}{|c|}{ Category of road user } & \multicolumn{2}{|c|}{ Pedestrians } & \multicolumn{2}{|l|}{ Cyclists } & \multicolumn{2}{|c|}{ Vehicle Users } & \multicolumn{2}{|c|}{ Age 5-11 } & \multicolumn{2}{|c|}{ Age 12-16 } \\
\hline & & $\begin{array}{l}\text { Week } \\
\text { before } \\
\text { change }\end{array}$ & $\begin{array}{l}\text { Week } \\
\text { after } \\
\text { change }\end{array}$ & $\begin{array}{l}\text { Week } \\
\text { before } \\
\text { change }\end{array}$ & $\begin{array}{l}\text { Week } \\
\text { after } \\
\text { change }\end{array}$ & $\begin{array}{l}\text { Week } \\
\text { before } \\
\text { change }\end{array}$ & $\begin{array}{l}\text { Week } \\
\text { after } \\
\text { change }\end{array}$ & $\begin{array}{l}\text { Week } \\
\text { before } \\
\text { change }\end{array}$ & $\begin{array}{l}\text { Week } \\
\text { after } \\
\text { change }\end{array}$ & $\begin{array}{l}\text { Week } \\
\text { before } \\
\text { change }\end{array}$ & $\begin{array}{l}\text { Week } \\
\text { after } \\
\text { change }\end{array}$ \\
\hline Spring & $\begin{array}{l}\text { Morning period } \\
\text { Evening period }\end{array}$ & $\begin{array}{r}36 \\
130\end{array}$ & $\begin{array}{r}23 \\
116\end{array}$ & $\begin{array}{l}36 \\
75\end{array}$ & $\begin{array}{l}32 \\
69\end{array}$ & $\begin{array}{l}205 \\
518\end{array}$ & $\begin{array}{l}205 \\
459\end{array}$ & $\begin{array}{l}20 \\
85\end{array}$ & $\begin{array}{l}14 \\
66\end{array}$ & $\begin{array}{l}25 \\
80\end{array}$ & $\begin{array}{l}20 \\
80\end{array}$ \\
\hline Autumn & $\begin{array}{l}\text { Morning period } \\
\text { Evening period }\end{array}$ & $\begin{array}{r}35 \\
119\end{array}$ & $\begin{array}{r}26 \\
128\end{array}$ & $\begin{array}{r}57 \\
103\end{array}$ & $\begin{array}{l}46 \\
99\end{array}$ & $\begin{array}{l}276 \\
547\end{array}$ & $\begin{array}{l}273 \\
572\end{array}$ & $\begin{array}{l}12 \\
67\end{array}$ & $\begin{array}{l}12 \\
74\end{array}$ & $\begin{array}{l}32 \\
91\end{array}$ & $\begin{array}{l}28 \\
72\end{array}$ \\
\hline
\end{tabular}


data are applicable to most areas of a mixed geography and are comparable with other studies of road traffic accident casualties.

The case for the abandonment of BST has come in the main from Scotland and from the farming and construction industries. Apart from the obvious inconvenience and higher costs involved with darker mornings, one of the main arguments has been that there is a detrimental effect on road traffic accident numbers. It can be seen from this study that this anticipated rise in accidents with the change to BST is not seen. The overall effect of BST is shown to be beneficial on road traffic accident statistics.

I therefore conclude that the introduction of year long BST would result in an overall benefit in reducing the numbers of road traffic accidents in the peak morning and evening periods.
I thank Mr John Moss, chief road safety officer for Cheshire, for his considerable assistance in the preparation of this paper.

1 Hillman M. Time for change-setting clocks forward by one hour throughout the year. London: Policy Studies Institute, 1993.

2 The potential accident benefits of re-introducing British Standard Time. Transport and Road Research Laboratory, LF $1027,1986$.

3 Broughton J, Steadman RJ. The potential effects on road casualties of Double British Summer Time. Research report No 228. Transport and Road Research Laboratory, 1989.

4 Road Accidents Great Britain 1993: The casualty report. London: Department of Transport, 1994.

5 Atkins RM, Turner WH, Duthie RB, Wilde BR. Injuries to pedestrians in road traffic accidents. $B M \mathcal{F}$ 1988;297: pedestrians

6 Teanby DN, Gorman DF, Boot DA. Pedestrian accidents on Merseyside: the case for criminalisation of jaywalking. on Merseyside: the case

7 Dove AF, Pearson JCG, Weston PAM. Data collection from road traffic accidents. Arch Emerg Med 1986;3:193-8.

8 British Standard Time and road casualties. Road Research Laboratory, LF 213, 1970.

9 Tunbridge RJ, Everest JT, Wild BR, Johnstone RA. An indepth study of road accident casualties and their injury patterns. Research report No 136. Transport and Road Research Laboratory, 198810 Teanby $D$. Underreporting of pedestrian road accidents. BMF 1992;304:422.

\title{
ADVANCED LIFE SUPPORT GROUP
}

\section{Major Incident Medical Management and Support} Courses: to be held in various centres throughout the UK in 1996. This is a three day course in "life support style" designed to train health service personnel to provide an effective response at a major incident.

Fee $£ 300.00$

Advanced Paediatric Life Support Courses: to be held in various centres throughout the UK in 1996. This is a three day course designed to provide training which will enable doctors and nurses to deal efficiently with all paediatric emergencies. The course is modular and has sections on paediatric resuscitation, serious illness and serious injury.

Fee varies according to centre. Range $£ 300.00-£ 350.00$.

\author{
Inquiries for both courses to: \\ Jenny Antrobus \\ Advanced Life Support Group \\ A\&E Dept \\ Hope Hospital \\ Stott Lane \\ Salford M6 8HD \\ Tel 01617874345
}

